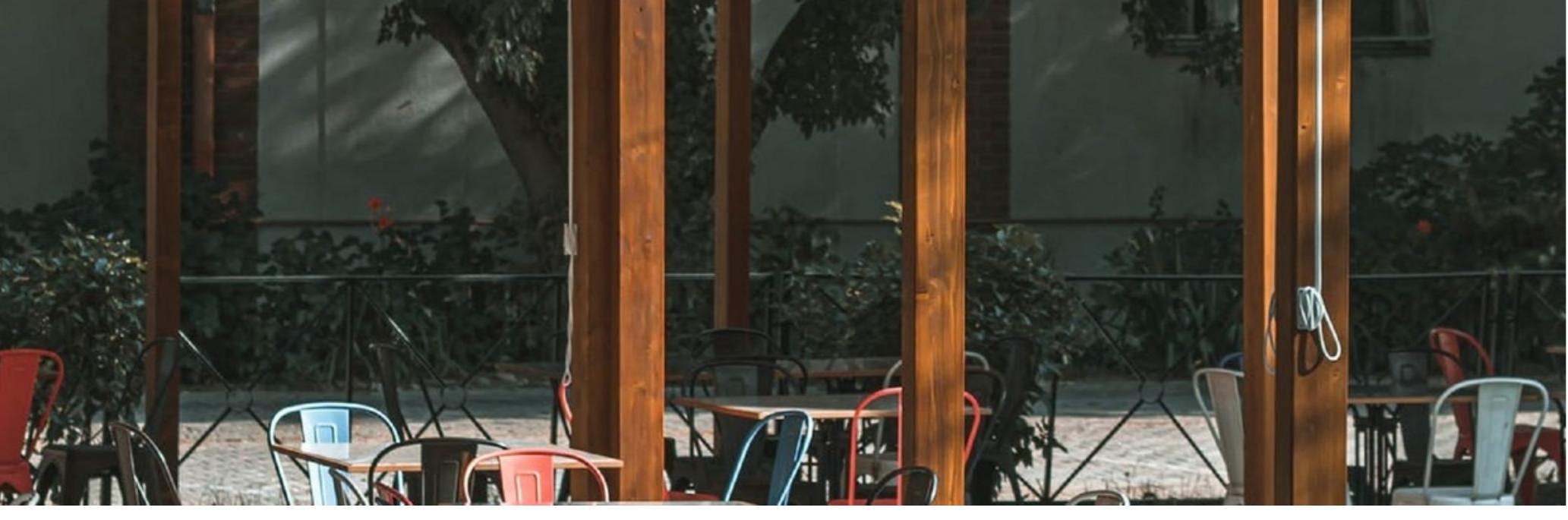

\title{
Pandemic SARS CoV -2 - a Romanian perspective. The perception of a septuagenarian doctor
}

\author{
Authors: Eugen Carasevici \\ Submitted: 2. August 2020 \\ Published: $\quad 3$. August 2020 \\ Volume: 7 \\ Issue: $\quad 4$ \\ Affiliation: TRANSCEND (Center of Fundamental Research and \\ Experimental Development in Translational Medicine), Regional \\ Institute of Oncology in lasi, Romania \\ Languages: English \\ Keywords: $\quad$ COVID-19, Romania, Public Health, Lifestyle, SARS-CoV-2 \\ Categories: News and Views, Medicine \\ DOI: $\quad$ 10.17160/josha.7.4.702
}

Abstract:

The SARS-CoV-2 pandemic reveals everywhere in the world, and of course also in Romania, individuals' ability to respond to danger, but also their degree of compliance with the medical, social and political regulations in order to act responsibly. Behavioral diversity, level of education, media influence have left their mark on the response of society to the spread of the infection to such an extent that the number of cases has resumed its daily growth. The perspective of the pandemic evolution remains unclear, and Romania, despite the medical effort made, does not seem to have had the complete revelation of the danger yet. Humanity lost in self-admiration does not yet realize the mortal danger of this virus.

\section{JOSHA Joumalossimene. Humanities and Arts




\section{Pandemic SARS CoV -2 - a Romanian perspective.}

\section{The perception of a septuagenarian doctor}

\section{By Professor Dr. Eugen Carasevici}

Affiliation: TRANSCEND (Center of Fundamental Research and Experimental Development in Translational Medicine), Regional Institute of Oncology in lasi, Romania

\section{Abstract:}

The SARS-CoV-2 pandemic reveals everywhere in the world, and of course also in Romania, individuals' ability to respond to danger, but also their degree of compliance with the medical, social and political regulations in order to act responsibly.

Behavioral diversity, level of education and media influence have left their mark on the response of society to the spread of the infection to such an extent that the number of cases has resumed its daily growth.

The perspective of the pandemic evolution remains unclear, and Romania, despite the medical effort made, does not seem to have had the complete revelation of the danger yet.

Humanity lost in self-admiration does not yet realize the mortal danger of this virus. 


\section{JOSHA}

Journal of Science, Humanities and Arts

I have developed a new habit. Every day at 1 p.m. I read the medical bulletin. For instance, today, June 21, I find out that, so far, in Romania, there have been confirmed 24.045 cases of people infected with coronvirus, 1.512 deaths, while 16.911 were declared cured and discharged home. In the last 24 hours 315 new cases have been reported. Considering the fact that 330 new cases were announced yesterday, this is the fifth day in a row when the number of reported new cases exceeds 300 . I also find out that, at this moment, 195 patients are hospitalized in the intensive care services and 1.309 people are in institutionalized quarantine. Another 76.621 people are in isolation at home under medical supervision. Moreover, at the national level 626.330 tests have been processed so far. We also bring our contribution to this national effort with over 300 tests being performed per day in the molecular biology laboratories of the TRANSCEND $\quad$ Center see http://joshajournal.org/en/categories/medicine/articles/transcend-a-new-translational-medicinehub-at-the-east-edge-of-european-union).

The history of the evolution of SARS-CoV-2 infection in Romania is easy to follow on the internet (https://en.wikipedia.org/wiki/COVID-19 pandemic in Romania)

After two months of severe restrictions during the state of emergency declared throughout the territory, it was possible to reduce the daily number of infected people to 119 on June 1, 2020. Then, in the next phase, called state of alert, the reduction of restrictions led to a sharp increase in the number of cases. The perspective of what will follow is uncertain and depends on each individual's approach of the situation.

If I think about what is happening, I realize that we depend on each other to the last man on the planet. This is also the great difficulty. No country, and therefore neither Romania, can foresee the future limited only to its own borders. The pandemic is global and threatens the species. What differs from one country to another, from one nation to 


\section{JOSHA}

Journal of Science, Humanities and Arts

another, is the reaction to danger. This reaction depends on the character of each nation. In Romania, the answer is very heterogeneous and obviously in relation to the level of knowledge and the coping mechanisms used in the face of stress, or maybe even in relation to the national fund of mental energy and perception. Thus, from panic to total denial of danger, we have a wide range of behaviors. Attitudes such as consenting to the medical appeal to behavior appropriate to the crisis and public cohesion, mocking the protection measures and accusing the world occult governance are all present in Romania. Reactions could be stratified according to the source of human milieu and government representatives are no exception.

The SARS-CoV-2 pandemic will continue worldwide and in Romania. The medical world itself and public health systems have been caught unprepared. The disease remains largely unknown, with capricious evolution and variable response to empirically established treatments. We do not know if the vaccines that are to be applied as soon as they are produced, skipping the usual testing phases, will also quench the pandemic, given that we do not know well enough how the immune system operates in counteracting the infection.

What can be seen, and I do not know how much everyone appreciates it, are the effort and sacrifices of the medical body involved both worldwide and in Romania. But the global evolution of the infection has also diverted the medical system from the care and treatment of chronic diseases with high prevalence. Biomedical research has also been financially sidetracked to find a solution for COVID 19, with funding for research in other fields diminished. I am afraid that both in the world and in Romania the perspective is unclear, and the future remains uncertain.

The battle is fierce and nowhere does it depend only on the medical staff, but also on the conduct of the officials in charge and, finally, on each individual. The virus has 
generated a global attack, and the response should be of the same rank. Romania is among the nations involved.

\section{About the author:}

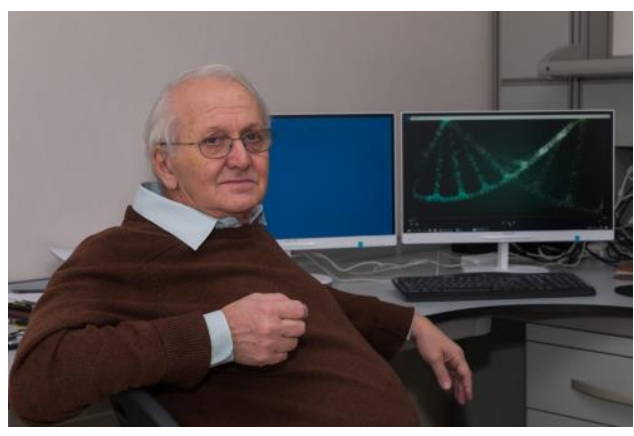

\section{Professor Dr. Eugen Carasevici,} eugen.carasevici@gmail.com

$\mathrm{He}$ is a Senior Research Consultant at TRANSCEND (Center of Fundamental Research and Experimental Development in Translational Medicine), Regional Institute of Oncology in lasi, Romania. He graduated the Faculty of Medicine in 1969 at Gr.T. Popa University of Medicine and Pharmacy, lasi. After two years of internship, he worked in the oncology chemotherapy department of Radiology-Oncology Clinic at the University Hospital from 1971 to 2013. He was attracted to the field of tumor immunology and set up laboratories in this research profile, and eventually the TRANSCEND Research Center. Between 1992 and 2014 he was a Professor for Immunology and Coordinator for PhD students in Immunology-Immunopathology at Gr.T.Popa University of Medicine and Pharmacy. 